\title{
'Garland sign' in amyotrophic lateral sclerosis
}

Sir,

A 37-year-old lady presented with pure motor, asymmetrical onset, progressive quadriparesis with wasting of hands and feet of one year duration, with dysphagia, dysarthria, and emotional incontinence of four months duration. On examination, she had upper motor neuron (UMN) and lower motor neuron (LMN) signs in bulbar muscles, upper and lower limbs without involvement of extraocular movements. Rest of the neurological examination was normal. She satisfied the El Escorial criteria for definite amyotrophic lateral sclerosis (ALS). Her electrodiagnostic studies showed evidence of preganlionic neurogenic lesion involving bulbar, cervical, thoracic, and lumbosacral spinal segments. Her work up for secondary causes of anterior horn cell disease was negative.

She was evaluated with magnetic resonance imaging (MRI) of the brain and spinal cord. MRI brain showed all the characteristic features of ALS including T2 hyperintensity extending along corticospinal tract from centrum semiovale to crus cerebri bilaterally. T2 hypointensity was noted in precentral gyrus. MRI cervical spine showed $\mathrm{T} 2$ hyperintensity involving the anterolateral column of the spinal cord. The coronal T2 image was forming a characteristic 'garland pattern' 

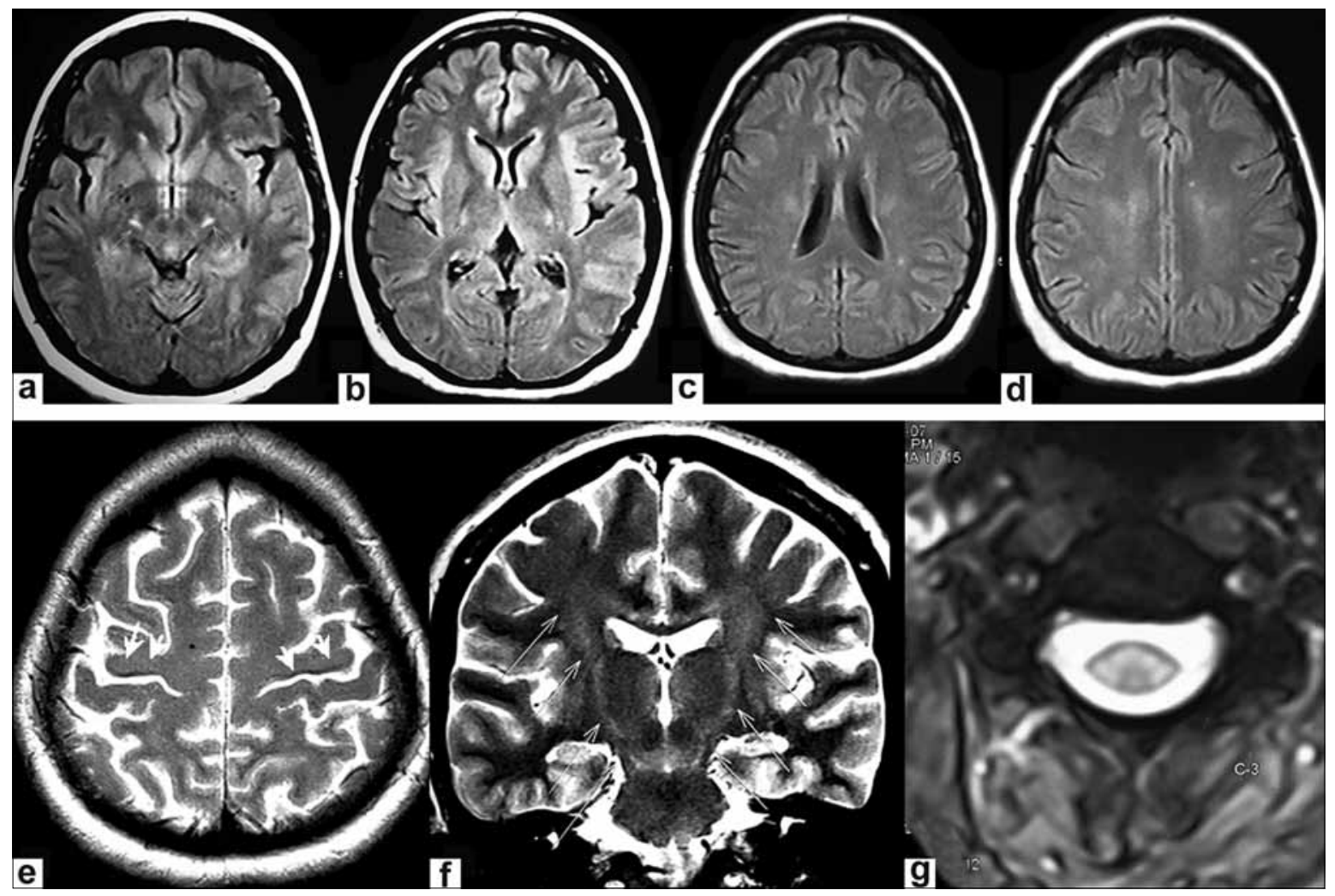

Figure 1: (a) Magnetic resonance imaging axial FLAIR sequence showing hyperintensity along corticospinal tracts at the level of crus cerebri; (b) posterior limb of internal capsule; (c) corona radiata; (d) and centrum semiovale; (e) MRI axial T2 sequence showing hypointensity in motor cortex bilaterally (arrow heads); (f) MRI coronal T2 sequence showing hyperintensity along corticospinal tract (arrows) and corpus callosum forming a 'Garland pattern'; (g) MRI axial T2 sequence of the cervical cord showing hyperintensity in anteroalateral segments with sparing of posterior segment

of hyperintensity extending along corticospinal tracts as well as involving corpus callosum [Figure 1]. This peculiar imaging appearance has hitherto not been reported in a classical case of ALS. T2-weighted image showing high signal intensity involving the corticospinal tract extending into the anterolateral column of the spinal cord has been described. ${ }^{[1]}$ Involvement of the corpus callosum has also been reported. ${ }^{[2]}$ In addition, T2weighted MRI typically demonstrates low signal intensity in the motor cortex; this finding has been attributed to $\mathrm{T} 2$ shortening due to iron deposition. ${ }^{[1]}$ A lesion distribution simulating a garland has been described with Alexander disease, metastatic colorectal adenocarcinoma, and acute postinfectious glomerulonephritis. ${ }^{[3-5]}$

\section{Atma Ram Bansal, Gopal Krishna Dash, Ashalatha Radhakrishnan, Chandrasekharan Kesavadas ${ }^{1}$, Muraleedharan Nair \\ Departments of Neurology, and ${ }^{1}$ Imaging Sciences \& Interventional Radiology, Sree Chitra Tirunal Institute for Medical Sciences and Technology, Trivandrum, Kerala, India. E-mail: chandkesav@yahoo.com}

\section{References}

1. Waragai M. MRI and clinical features in amyotrophic lateral sclerosis. Neuroradiology 1997;39:847-51.

2. Van Zandijcke M, Casselman J. Involvement of corpus callosum in amyotrophic lateral sclerosis shown by MRI. Neuroradiology 1995;37:287-8.

3. Van der Knaap MS, Ramesh V, Schiffmann R, Blaser S, Kyllerman M, Gholkar A, et al. Alexander disease: Ventricular garlands and abnormalities of the medulla and spinal cord. Neurology 2006:66:494-8.

4. Lewis MR, Deavers MT, Silva EG, Malpica A. Ovarian involvement by metastatic colorectal adenocarcinoma: Still a diagnostic challenge. Am J Surg Pathol 2006;30:177-84

5. Sorger K, Gessler U, Hübner FK, Köhler H, Schulz W, Stühlinger W, et al. Subtypes of acute postinfectious glomerulonephritis. Synopsis of clinical and pathological features. Clin Nephrol 1982;17:114-28.

Accepted on 31-03-2009

DOI: $10.4103 / 0028-3886.53273$ 